of JDR-MT in Haiti. The JDR-MT consisted of 27 members, including four medical doctors, seven nurses, one pharmacist, one radiologist, one medical technologist, two emergency medical technicians, and 11 logisticians. The JDR-MT was equipped with medicines for 1,000 patients, a portable x-ray system, and ultrasound diagnostic equipment. The JDR-MT performed relief activities at Leogane City, which was $40 \mathrm{~km}$ west of the capital of Port-au-Prince, and was the first medical team that entered the Leogane area after the earthquake. The JDR-MT treated 534 patients for eight days. The male-female ratio of total patients was $180 / 354$, and the male-female ratio of 242 injured cases treated by the JDR-MT was 80/162. Among the patients treated by the JDR-MT, 100 were diagnosed as bone fractures with the portable $\mathrm{x}$-ray system. There were 17 cases of open bone fractures and 15 cases of pelvic fractures. The malefemale ratios were $28 / 72,4 / 13$, and $1 / 14$ respectively. The total number of female patients was approximately double compared with the number of male patients in this experience. The proportion of female patients was much higher in the cases of severe injury, such as open bone fractures and pelvic fractures.

Prehosp Disaster Med 2011;26(Suppl. 1):s27-s28

doi:10.1017/S1049023X11001038

\section{(A102) Training Agricultural Emergency Responders}

\section{P.L. Cowen}

Veterinary Services, Professional Development Staff, Fort Collins, CO, United States of America

Training Agricultural Emergency Responders by Paula L. Cowen, D.V.M., Director, Professional Development Staff, Veterinary Services, Animal Plant Health Inspection Service, United States Department of Agriculture

Abstract: Background Emergency Response is a critical component of our Animal Agriculture infrastructure. The ability to deploy trained personnel to handle any kind of emergency is key to quickly containing any disaster and mitigating the effects. This training is provided by a number of federal agencies, universities as well as at the state and local level. Body Several training strategies are employed by a number of different entities. Training is available on-line, in the classroom, with wet labs using live animals, through exercises and case studies. An overview of training and education of Agricultural Emergency Response personnel across the United States will be covered with a more in depth look at the training provided by the Animal Plant Health Inspection Service.

Conclusion: The Professional Development Staff provides technical training in disease identification and control, emergency response, import/export, and other topics as needed. Protecting and promoting American Animal Agriculture is our core mission. Veterinary Services provides leadership at the intersection of Animal and Public Health concerns.

Prehosp Disaster Med 2011;26(Suppl. 1):s28

doi:10.1017/S1049023X1100104X

\section{(A103) Understanding Terror Medicine}

L. Cole

Division of Global Affairs, Newark, United States of America

The term terror medicine emerged early in the 21st century to describe medical issues associated with terrorist events.
While related to emergency and disaster medicine, the field also includes several features that are specific to terrorist attacks. The Israeli healthcare experience as related to terrorist attacks during the intifada (2000-2006), provides a base for comparison to responses elsewhere including to events in Oklahoma City (1995), Madrid (2004), and London (2005). Terror medicine covers four broad areas. First is preparedness, which encompasses hospital surge capacity, training and exercises, and the stockpiling of medical provisions for conventional and non-conventional attacks. Second is incident management, which includes protocols for on-site care, triage, distribution of victims to hospitals, and hospital-receiving procedures. Third is mechanism of injuries and responses, which ranges from determining treatment priorities in someone with multiple injuries (burn, crush, ruptured organs, etc.) to dealing with biological, chemical, or radiological exposures. Fourth, psychological consequences, involves care for acute and longterm emotional effects of a terrorist attack. Growing interest in terror medicine has been manifested in recent publications and conferences. (Egs., SC Shapira and LA Cole, Terror Medicine: Birth of a Discipline, J Homeland Security and Emerg Management, Vol. 3, No. 2 [2006] http://www.terrormedicine. com/publications_files/Terrormedicine.pdfAC; SC Shapira, JS Hammond, LA Cole, eds., Essentials of Terror Medicine, NY: Springer [2009]; Symposiums on Terror Medicine and Security, University of Medicine and Dentistry of New Jersey [Newark, NJ, July 2009; Montclair, NJ, Sept. 2010]). Efforts to prevent terrorist attacks should be among a society's highest priorities. No less important are the requirements to prepare for, respond to, and recover from these events. The more that individuals and institutions become familiar with the essentials of terror medicine, the greater the protection they can provide to others.

Prehosp Disaster Med 2011;26(Suppl. 1):s28

doi:10.1017/S1049023X11001051

\section{(A104) Simulation in Disaster and Emergency Medicine G.E.A. Khalifa \\ Emergency Medicine, Abu Dhabi, United Arab Emirates}

Simulation: An activity or situation that produces conditions which are not real, but have the appearance of being real, used especially for testing something. Longman Dictionary of Contemporary English. Simulation has evolved over the centuries but has not been applied to medicine until the $20^{\text {th }}$ century with the introduction of virtual reality and computers. Prior to the 20th century simulation took the forms of physical models and cadavers. With the introduction of flight simulation there was an effort to move similar approaches into medicine. This was pushed by the demands of minimally invasive surgery and the introduction of robotics in surgery. In the 21st century in addition to cognitive task analysis tools we are beginning to see the migration of advanced intelligence tools to simulation. We are just at the beginning of how we will use adversarial reasoning in the medical environment and in high risk time constrained situations like Emergency Medicine. The practitioner of emergency medicine is at high risk for errors because of multiple factors including high decision density, high levels of diagnostic uncertainty, high patient acuity, and frequent distractions. Some 
authors have suggested that instructing physicians in "cognitive forcing strategies" or "metacognition" will help reduce the amount of cognitive error in medical practice. It has been said "[There is an] ethical obligation to make all efforts to expose health professionals to clinical challenges that can be reasonably well simulated prior to allowing them to encounter and be responsible for similar real-life challenges.” TYPES OF SIMULATION • Verbal $\bullet$ Tactile $・$ Visual $\cdot$ Situational $・$ Environmental TYPES OF SIMULATION TRAINING • Standardized patients (role play) $\bullet$ Basic models (partial task trainers) $\bullet$ Simple level $\bullet$ Higher level - Mannequins $•$ Low fidelity $\cdot$ High fidelity $•$ Virtual patients $\bullet$ Screen-based; computer-based $\bullet$ COMBINATIONS • Augmented sp encounters with technology $\bullet$ Crises management HUMAN PATIENT SIMULATION • Realistic • Suitable for all levels $\bullet$ Safe $\bullet$ Wide variety of training programs $\bullet$ Expensive ADVANTAGES OF SIMULATION $\cdot$ Patients are never at risk - Serious but infrequent events, in predictable times and places $\bullet$ Errors can be allowed to occur, and play-out $\bullet$ Rehearsal, repetition, mastery $\cdot$ Crisis management simulation, planning - Reduces institutional liability - Increases operational confidence $\bullet$ Produces rapid results $\bullet$ Allows team training $\bullet$ Increases institutional prestige The use of high fidelity simulations to train multidisciplinary teams in critical environments is well established. References: 1. Croskerry P, Wears RL, Binder LS. Setting the educational agenda and curriculum for error prevention in emergency medicine. Acad Emerg Med. 2000;7:1194200. 2. Croskerry P. The cognitive imperative: thinking about how we think. Acad Emerg Med. 2000;7:1223-31. 3. Croskerry P. The feedback sanction. Acad Emerg Med. 2000;7:1232-8. 4. Handler JA, Gillam M, Sanders AB, Klasco R. Defining, identifying, and measuring error in emergency medicine. Acad Emerg Med. 2000;7:1183-8. 5. Schenkel S. Promoting patient safety and preventing medical error in emergency departments. Acad Emerg Med. 2000;7:1204-22. 6. Croskerry P. The importance of cognitive errors in diagnosis and strategies to minimize them. Acad Med. 2003;78:775-80.

Prehosp Disaster Med 2011;26(Suppl. 1):s28-s29 doi:10.1017/S1049023X11001063

(A105) A Core Curriculum for Nurses in Disaster Preparedness and Response

L. Chang, ${ }^{1}$ S.M. Briggs ${ }^{2}$

1. Patient Care Services, Department of Nursing, Boston, United States of America

2. Boston, United States of America

Background: Nurses play an essential role in disaster response. All health care responders, including nurses, must have knowledge of the key principles of disaster medicine. The International Trauma and Disaster Institute (ITDI) at Massachusetts General Hospital has developed a core curriculum for Mass Casualty Incident (MCI) management. The curriculum provides all members of the multidisciplinary disaster team with the fundamentals of the MCI response. The proposed concurrent session will report on understanding of the fundamental knowledge in disaster medicine and preparedness for nurses in local and international disaster responses.

Discussion and Observations: Disasters follow no rules. Traditionally, medical providers have held the erroneous belief that all disasters are different, especially those involving terrorism. In reality, all disasters, regardless of etiology, have similar medical and public health consequences. A consistent medical approach to disasters, based on an understanding of their common features and the response they require, is becoming the accepted practice throughout the world. This strategy, called the MCI response, has the primary objective of reducing the mortality/morbidity caused by the disaster. The Advanced Disaster Medical Response (ADMR) Course, available in eight languages, including Chinese, is designed to train nurses in the ABC's of basic medical and public health disaster care. The delivery of optimal care in a disaster relies on a common understanding of each health professional's role and common mastery of defined essentials of disaster response such as the Incident Command System, field triage, decontamination, care of specific injuries, environmental considerations, psychological response to disasters, and care of the dead and their families. Understanding key principles and training in medical disaster response will guide nurses in disaster preparedness and response to future disasters.

Prehosp Disaster Med 2011;26(Suppl. 1):s29 doi:10.1017/S1049023X11001075

\section{(A106) Nursing Simulation in Disaster Management D. Moore, ${ }^{1}$ K. Atchison, ${ }^{2}$ J. Boone ${ }^{3}$ \\ 1. Nursing, Costa Mesau, United States of America \\ 2. Nursing, Anaheim, United States of America \\ 3. Director of Global Studies, Ontario, United States of America}

In the United States in 2010, there were 81 federal disasters, for this reason and at the request of our clinical partners, when West Coast University (WCU) started its Baccalaureate of Science in Nursing (BSN) program in 2008, it recognized the need to have a course in disaster management. The Disaster Management course was developed in concert with other parts of the curriculum such as Leadership, Physical Assessment, Critical Care courses to help students focus their assessment and intervention skills to prepare them to be future responders. As a component of the skill development, simulation exercises were developed in the simulation center within the college of nursing. To prepare students to respond to disasters, a variety of scenarios were developed to meet national patient safety goals and various types of disaster and emergency situations. In the scenarios students learn how to work as a team, follow the chain of command, assess and rapidly intervene to such medical crisis such as hemorrhaging, trauma, burns, cardiac arrest and respiratory arrest. They also learn how to delegate to the appropriate personnel as well as leadership skills. Students find this educational and reassuring to be able to practice these very high level sentinel events in a secure environment where they will get immediate feedback not only from instructors but from their peers. Preliminary research have identified students having significant improvement in their clinical skills from the first to the third exercise in regards to assessment, intervention, communication, and delegation. We have received feedback from our clinical partners that our students are better prepared than their current emergency staff in regards to disaster management and to that end we plan to work with our clinical partners to 